Egyptian

Orthodontic Journal

\title{
THE EFFECT OF BONE ANCHORED MAXILLARY PROTRACTION ON MAXILLARY- MANDIBULAR DIVERGENCY
}

\author{
Ola Mohamed*, Ahmed Abdel-Fattah**, \\ Mohamed Nadim****, Tamer Abdel-Bary****
}

ABSTRACT:

Introduction: This study was carried out to investigate the effect of bone anchored maxillary protraction (BAMP) on maxillarymandibular divergency during the treatment of growing patients with Class III malocclusion Methods: The sample of this study consisted of ten subjects (5 males and 5 females), (9-12 years old). Each treated patient had four miniplates inserted between the lower left and right lateral incisor and canine and on the left and right infrazygomatic crest of the maxillary buttress. Class III elastics were applied between the miniplates on each side for twenty four hours a day. Lateral cephalograms of each patient were evaluated at the beginning of treatment (T1), and at the end of active treatment (T2). The effect of treatment was compared to the effect of growth changes in a matched untreated control group of the same malocclusion. Results: the Pal-SN angle decreased $-1.30^{\circ}$, the $\mathcal{M P}-S \mathcal{N}$ angle decreased $-0.60^{\circ}$, the Go angle decreased $-2.10^{\circ}$, and the MP-PaL angle increased $1.20^{\circ}$. Conclusions: the BAMP approach induced a more counterclockwise rotation of the palatal plane than the mandibular plane that resulted in increase of Maxillomandibular divergency, but it was insignificant compared to the control group.

\footnotetext{
* Postgraduate student, Department of Orthodontics, Suez Canal University

${ }^{* *}$ Professor of Orthodontics, Faculty of Dentistry, Suez Canal University

${ }^{* * * *}$ Assistant Professor of Orthodontics, Faculty of Dentistry, Suez Canal University

${ }^{* * * *}$ Assistant Professor of Oral Surgery, Faculty of Dentistry, Suez Canal University
} 
Egyptian

Orthodontic Journal

\section{INTRODUCTION}

Over a century many treatment approaches of Class III malocclusion have been established with increasing emphasis on maxillary orthopedic to protract the maxilla. Face mask with palatal expansion approach has been used even if no need for transverse occlusal correction ${ }^{1}$. The rationale for expansion is to minimize the resistance of bony buttresses around the maxilla, splint the maxillary teeth, and correct the posterior crossbite when present. Face mask without expansion approach has also been advocated using passive appliance ${ }^{2}$. An anticipated forward positioning of the maxillary dentition relative to mandibular teeth produces an increased maxillary width. Anchorage loss such as (extrusion of maxillary molars, forward movement of maxillary molars and incisors, and clock wise rotation of the mandible) represents a limitation to protract the maxilla. Skeletal anchorage (implant embedded in the maxillary bone) has been used as an adjunct to facemask to minimize these side effects $6,7,8,9$. Recently the use of implanted zygomatic and mandibular plates along with Class III elastics with pure maxillary orthopedics has been reported $^{10,11}$. The aim of the present study was evaluate the effect of the bone anchored maxillary protraction treatment during growth on maxilla mandibular divergency.

\section{MATERIALS \&METHODS}

\section{Subjects:}

The sample consisted of two equal groups. Each group consisted of 10 patients with Class III malocclusion.

\section{BAMP group}

The treatment group consisted of ten subjects ( 5 males and 5 females), (9-12 years old). All subjects had dentoskeletal Class III malocclusion with maxillary retrognathism where the SNA angle was less than 80 degrees. At the beginning of the treatment (T1) all subjects were in pre pubertal or pubertal stage of skeletal maturity (Cs1-Cs3) according to cervical vertebral maturation method ${ }^{10}$ Fig 1. Each patient had two conventional cephalograms at the beginning of treatment (T1), and one year later (T2). All subjects had a signed informed consent by their parents before the treatment. 


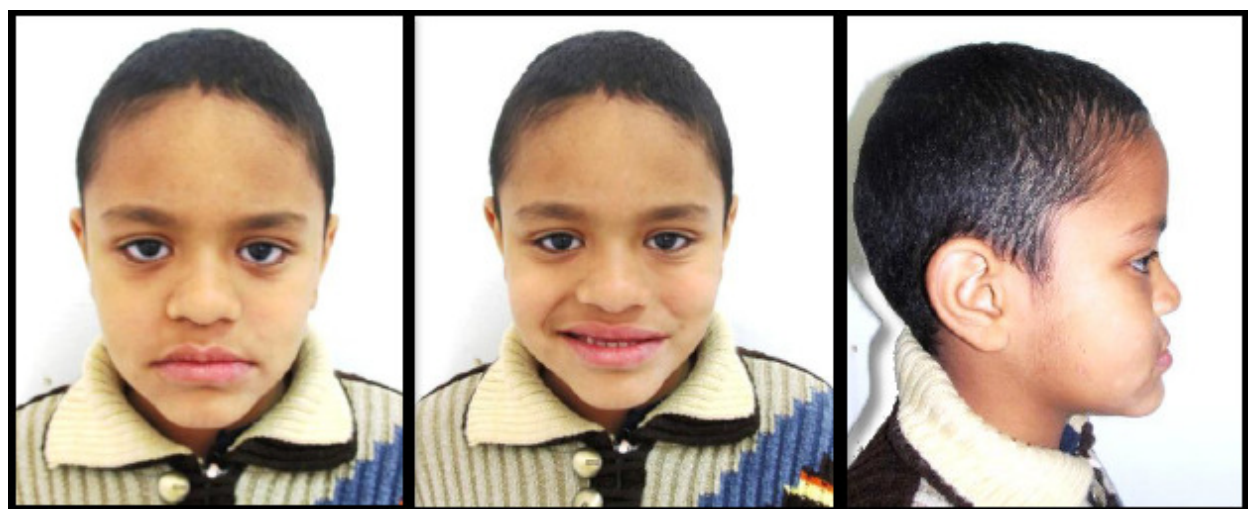

Fig. (1): Extra-oral views of a Patient had a skeletal Class III malocclusion with maxillary retrognathism.

\section{Control group}

The control group of ten subjects ( 7 males and 3 females) was chosen from a previous study ${ }^{11}$ Class III malocclusion with maxillary retrognathism where the SNA angle was less than 80 degrees). Chronological age ( 9 - 12 years old) at mid pubertal stage. All subjects were under observation for one year, received no treatment, and had two conventional cephalograms at the beginning of treatment (T1), and one year later (T2).

\section{Methodology:}

\section{Bone anchored maxillary protraction (BAMP) orthopedic protocol:}

\section{Insertion of miniplates:}

For each patient, four miniplates* were inserted on the left and right infrazygomatic crest of the maxillary buttress and between the lower left and right lateral incisor and canine. The miniplates were secured to the bone by two screws ( $1.8 \mathrm{~mm}$ diameter- $6 \mathrm{~mm}$ length) (HUBIT, Seoul, Korea). The extensions of the plates extended at the attached gingiva near the mucogingival junction. Seven miniplates showed mobility. Five of them showed mobility after loading and two showed mobility associated with infection before loading. The seven miniplates were removed and successfully replaced after one month to allow for tissue healing. All miniplates were inserted by a single surgeon. 
Egyptian

Orthodontic Journal

\section{Applying the load:}

Three weeks after surgery, the miniplates were loaded. Class III elastics were applied with an initial force of about $300 \mathrm{gms}$ on each side, increased to $350 \mathrm{gms}$ after one month of traction, And to $450 \mathrm{gms}$ after two months of traction.

\section{Removal of miniplates:}

Three months after the active treatment completion all miniplates were removed under local anesthesia Fig 2. All results were tabulated \& statistically analyzed using Student $t$ test and Paired $t$ test.

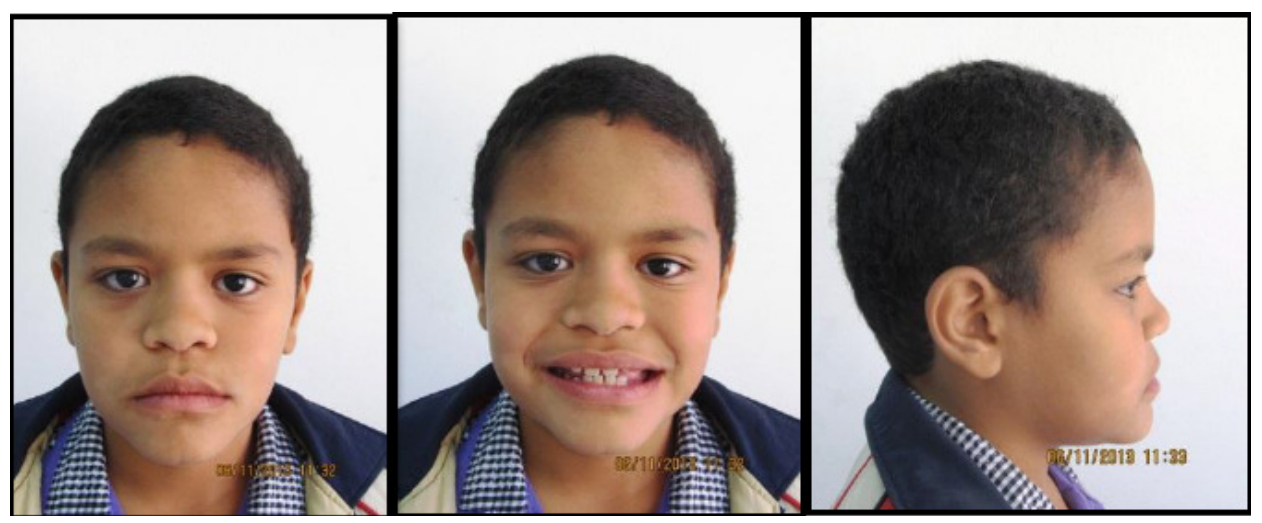

Fig. (2): Extra oral views of a patient showing Class III correction achieved with BAMP orthopedic protocol.

\section{RESULTS}

The Pal-SN angle showed an insignificant difference $(\mathrm{P}>0.05)$ when compared to the control group and decreased $\left(-1.30^{\circ}\right)$ compared to $\left(0.15^{\circ}\right)$ increase of Pal-SN angle in the control group. There was a decrease in MP-SN angle of $\left(-0.60^{\circ}\right)$ in the BAMP group, and decrease in MP-SN angle of $\left(-0.85^{\circ}\right)$ in the control group that was insignificant $(\mathrm{P}>0.05)$ when compared to the control group .In the BAMP group the combined rotation of the maxillary and the mandibular planes resulted in increase of Maxillomandibular divergency with increase in MP-PaL angle of $\left(1.20^{\circ}\right)$ compared to the control group which showed an increase in the MP-PaL angle of $\left(0.40^{\circ}\right)$, but it was insignificant $(\mathrm{P}>0.05)$ table 1 . 
Egyptian

Orthodontic Journal

Table (1): Descriptive statistics and test of significance for the effect of treatment (before-after) on skeletal vertical angular cephalometric measurements for both groups.

\begin{tabular}{|l|c|c|c|c|c|}
\cline { 2 - 5 } \multicolumn{1}{c|}{} & \multicolumn{4}{c|}{ Group } & \multicolumn{1}{c|}{} \\
\hline \multirow{2}{*}{ Measurement } & \multicolumn{2}{c|}{ Group A } & \multicolumn{2}{c|}{ Group B } & \multirow{2}{*}{ p } \\
\cline { 2 - 5 } & Mean & S.D. & Mean & S.D. & \\
\hline Pal-SN & 0.15 & 1.10 & -1.30 & 2.31 & $0.090 \mathrm{NS}$ \\
\hline MP-SN & -0.85 & 1.81 & -0.60 & 1.78 & 0.759 NS \\
\hline Go angle & -0.50 & 0.70 & -2.10 & 3.18 & $0.137 \mathrm{NS}$ \\
\hline MP-PaL & 0.40 & 0.80 & 1.20 & 2.70 & $0.381 \mathrm{NS}$ \\
\hline Y axis (SGn-SN) & -0.50 & 0.52 & 1.10 & 3.38 & $0.156 \mathrm{NS}$ \\
\hline
\end{tabular}

Group A = Control.

Group B = BAMP.

S.D. $=$ Standard deviation

$\mathrm{P}=$ Probability level for the effect of group.

NS $=$ Insignificant $(\mathrm{P}>0.05)$

\section{DISCUSSION}

In this controlled study the effect of BAMP on Class III malocclusion treatment was investigated. Ten Class III malocclusion subjects were selected as a statistically accepted sample.

The treatment group showed a counterclockwise rotation of the palatal plane to $\mathrm{SN}$ of $\left(-1.30^{\circ}\right)$, while there was a clockwise rotation of the palatal plane to $\mathrm{SN}$ plane $\left(0.15^{\circ}\right)$ in the control group. There was no significant difference $(\mathrm{P}>0.05)$ between the BAMP group and the control group. This could be explained on the basis of the direction of force application between the maxillary and mandibular miniplates which was located below the center of resistance of the maxilla. This was in agreement with Hong et $\mathrm{al}^{(12)}$ and Kircelli et al ${ }^{(13)}$

The mandibular plane in both groups showed a counterclockwise rotation. 
This observation agrees with previous studies on BAMP protocol conducted by Cevidanes et $\mathrm{al}^{7}$ and De Clerck et $\mathrm{al}^{8}$ who reported a counterclockwise rotation of the mandibular plane and decrease of gonial angle.

This observation disagrees with previous studies on bone anchored face mask where they reported down \& backward rotation of the mandible. Singer et $\mathrm{al}^{6}$ reported an increase in SN-mandibular plane angle of $\left(2^{\circ}\right)$.

There was a different mandibular rotation in BAMP versus bone anchored face mask treatment protocol. The probable reason might have been due to the effect of the pulling force of the Class III elastics on the mandible in BAMP protocol, while there was a pushing force on the mandible in bone anchored face mask therapy.

\section{CONCLUSION}

Compared with growth changes of untreated Class III control group the BAMP approach induced an increase of Maxillomandibular divergency by a more counterclockwise rotation of the palatal plane than the counterclockwise rotation of the mandibular plane but it was insignificant.

\section{REFERENCE}

1. Toffol LD, Pavoni C, Baccetti T, Franchi L, Cozza P. Orthopedic treatment outcomes in Class III malocclusion. Angle Orthod. 2008; 78: 561-573.

2. Mandall N, DiBiase A, Littlewood S, Nute S, Stivaros N, McDowall R, Shargill I, Worthington H, Cousley R, Dyer F, Mattick R, Doherty B. Is early Class III protraction facemask treatment effective? A multicentre, randomized, controlled trial: 15-month follow-up. J Orthod. 2010; 37: 149-161.

3. Singer S L, Henry P J, Rosenberg I. Osseointegrated implants as an adjunct to facemask therapy: a case report. Angle Orthod. 2000; 70: $253-262$. 
4. Kircelli B H, Pektas Z O. Midfacial protraction with skeletally anchored face mask therapy: a novel approach and preliminary results. Am J Orthod Dentofacial Orthop.2008; 133: 440-449.

5. Kaya D, Kocadereli I, Kan B, Tasar F. Effects of facemask treatment anchored with miniplates after alternate rapid maxillary expansions and constrictions. Angle Orthod .2011; 81:639-646.

6. Sar C, Arman-Özçırpıcı A, Uçkan S, Yazıcı AC. Comparative evaluation of maxillary protraction with or without skeletal anchorage. Am J Orthod Dentofacial Orthop. 2011; 139:636-49.

7. Cevidanes L, Baccetti T, Franchi L, McNamara JA Jr, De Clerck H. Comparison of two protocols for maxillary protraction: bone anchors versus face mask with rapid maxillary expansion. Angle Orthod. 2010; 80:799-806.

8. De-Clerck H, Cevidanes L H, Baccetti T. Dentofacial effects of bone-anchored maxillary protraction: a controlled study on consecutively treated Class III patients. Am J Orthod Dentofacial Orthop. 2010; 138: 577-581.

9. Baccetti T, De Clerck HJ, Cevidanes LH, Franchi L. Morphometric analysis of treatment effects of bone-anchored maxillary protraction in growing Class III patients. Eur J Orthod. 2011; 33:121-125.

10. Baccetti T, Franchi L, McNamara JA Jr. The cervical vertebral maturation (CVM) method for the assessment of optimal treatment timing in dentofacial orthopedics. Seminar in Orthod. 2005; 11: 119-129.

11. Abdel-Ghany A $\mathrm{H}$. The effect of protraction face mask on the treatment of maxillary deficiency in two age groups. Ph. D thesis 1995, Cairo University.

12. Hong H, Ngan P, Han G, Qi LG, Wei SH. Use of on plants as stable anchorage for facemask treatment: a case report. Angle Orthod. 2005; 75: 453-460.

13. Kircelli B H, Pektaş Z O, Uçkan S. Orthopedic protraction with skeletal anchorage in a patient with maxillary hypoplasia \& hypodontia. Angle Orthod. 2006;76:156-163. 